\title{
Approaching Spiritual and Existential Care Needs in Health Education: Applying SOPHIE (Self-Exploration through Ontological, Phenomenological, and Humanistic, Ideological, and Existential Expressions), as Practice Methodology
}

\author{
Gulnar Ali ${ }^{1, *}$ and Nasreen Lalani ${ }^{2}$ (D) \\ 1 Health and Social Care, University of Wales Trinity Saint David, London SW9 6EJ, UK \\ 2 School of Nursing, Purdue University, West Lafayette, IN 47907, USA; lalanin@purdue.edu \\ * Correspondence: g.ali@uwtsd.ac.uk or gulnar.ali1@hotmail.com
}

Received: 14 July 2020; Accepted: 29 August 2020; Published: 3 September 2020

\begin{abstract}
Addressing existential and spiritual care needs, often remains a challenge in health education. Spirituality is a subjective human experience that shapes how individuals make meaning, construct knowledge, develop their own sense of reality, and bring personal and social transformation. To inspire health and social students at a London based University; learners were engaged into philosophical reasonings associated with the meaning to care. SOPHIE (Self-exploration through Ontological, Phenomenological and Humanistic, Ideological, and Existential expressions)-a reflective practice tool was applied during in-class activities from June 2019-2020. Using SOPHIE as a tool, students were encouraged to explore existential and ontological care aspects by engaging into transformative learning approaches. Participants identified their own existential and spiritual care needs by reflecting on their own meaning making process. SOPHIE enabled resilience and authenticity among learners as a reflexive discourse.
\end{abstract}

Keywords: self-care; authenticity; meaning making; ontology; reflective learning; spirituality and existential health

\section{Background}

Spiritual and existential care aspects have received a significant attention in adult learning and education. Spirituality is an important aspect of human experience that shapes how individuals make meaning, construct knowledge, develop their own sense of reality, and bring personal and social transformation (Langellier 2001; Tisdell and Tolliver 2003; Wattis et al. 2019). Spirituality is often regarded as synonymous with the institution of religion. However, these two concepts i.e., spirituality and religion are distinct (Koenig 2004). Spirituality can also be understood as the personal, inner, informal, and emotional aspect of connecting with oneself, the environment or with the sacred (Koenig 2004; Caldeira et al. 2016). Whereas religion is set of organized beliefs and practices, usually shared by a community or group (Koenig 2004). In health education, spirituality has been approached from a variety of perspectives, acknowledging diverse meanings and different associations from culture, beliefs, and philosophical backgrounds, to recognize person-centered care needs. The myriads of meanings and interpretations associated with the term spirituality often generates confusion and lack of clarity among healthcare professionals and educators (Kalkim et al. 2016; Wattis et al. 2017; Lalani 2020). This, in turn, leads to problems in incorporating spirituality into education and practice (Caldeira et al. 2016). Over the last three decades there have been numerous calls to integrate spirituality and spiritual 
care into health education (Ali et al. 2018). In the past, spirituality in education is more generally seen as the construction of knowledge or in dealing with religious pluralism in higher education settings, nonetheless a newer common perspective focus on meaning-making in adult learning as intricately related to the spiritual quest of adults (Tisdell 2001; Wattis et al. 2019). It has been suggested that attending to the spiritual dimension of adult learning is part of honoring the learner's self as well as her/his own life in the quest for meaning making (Tisdell 2001; Ali et al. 2018). However, there is no consensus about how this can be done as an essential learning component in health education (Ali et al. 2018; Wattis et al. 2019). Newer approaches and models are therefore needed to integrate this important dimension of spirituality in health education.

SOPHIE (Self-exploration through Ontological, Phenomenological, and Humanistic, Ideological, and Existential expressions), a heutagogical tool was developed by the author, to approach spiritual and existential care needs through meaning-making reflexive engagement, in health care education and practice (Ali and Snowden 2019). SOPHIE introduced a teaching intervention focusing on exploring existential and spiritual care needs in health education in June 2019-2020. Embedded with self-reflective activities such as art work, mindfulness, and poetry writing; SOPHIE was applied during in-class activities as part of core-learning sessions, threading across various undergraduate modules in health and social care such as Psychology (level 04), Principles of Health and Social care practice (level 05) at a London based University, where the researcher was also the main lecturer and module leader of the said courses.

\section{SOPHIE as an In-Class Teaching and Learning Intervention}

SOPHIE (Self-exploration through Ontological, Phenomenological, and Humanistic, Ideological, and Existential expressions) (Figure 1), recognizes several ontological and practice based reflexive components, approaching and addressing spiritual care needs in health education (Ali and Snowden 2019). Embracing the philosophy of holistic development, SOPHIE (Self-exploration through Ontological, Phenomenological, and Humanistic, Ideological, and Existential expressions) is a reflective framework to approach existential and spiritual care needs (Ali 2017). SOPHIE, in addition to socio-cultural, behavioral, and person-centered approaches, acknowledges ontological dimensions and embraces intentionality, reflexivity, and creativity so that existential and spiritual care needs of an individual could be recognized.

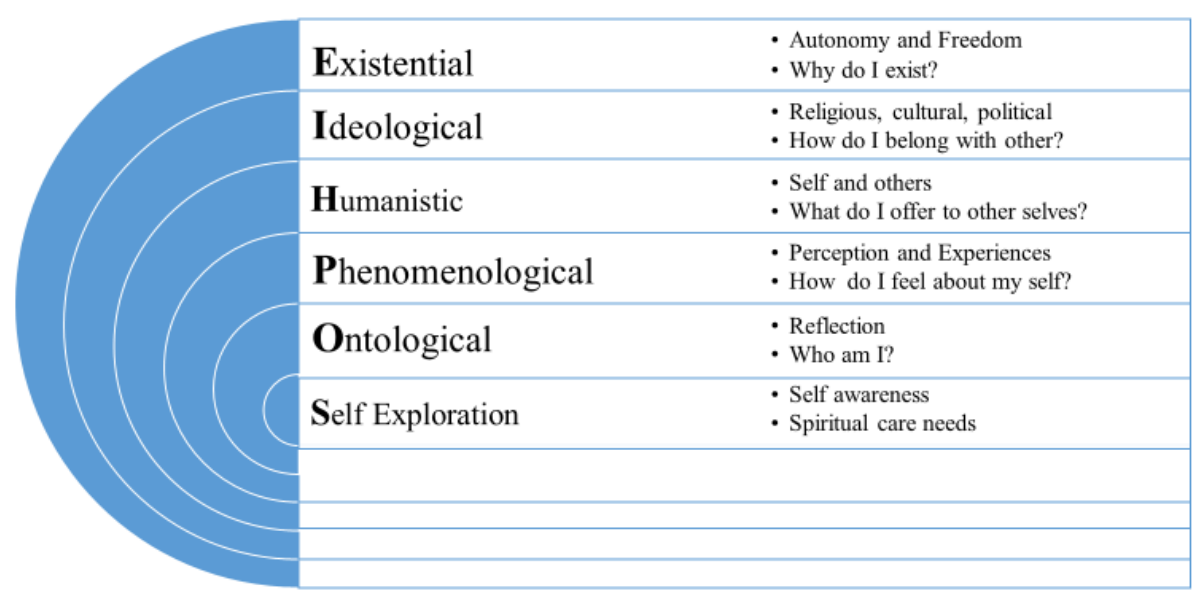

Figure 1. SOPHIE-Self-exploration through Ontological, Phenomenological, and Humanistic, Ideological, and Existential expressions) (Ali 2017).

Self-exploration-I v/s Me?

Ontological Aspect-Who am I?

Phenomenological aspect-How am I?

Humanistic aspect-What can I offer to others? 
Ideological aspects-How do I belong to others?

Existential Aspect-Why do I exist? What is the meaning of my life?

The aims of the in-class teaching intervention were as follows:

1. To explore the existential quest and meaning making process among students using self-reflective practices in health education.

2. To develop a deeper understanding of the spiritual care competencies and existential care aspects in practice settings.

3. To evaluate the efficacy of SOPHIE as a practice methodology, and to explore students' existential and spiritual care needs in higher education.

\section{Methodology}

In-class teaching interventions were not formally conducted as a research study; however, the principles of interpretative and constructive research paradigms were used to inquire about the experiences of students using SOPHIE as deep reflective methodology from June 2019-2020 (Robson and McCartan 2016). Multiple and embedded case study research design was found relevant to study students' responses and level of participation during class-based sessions (Yin 2014). For this study, each case was a cohort of students, across level 4 and 5 in Health and Social Care undergraduate studies. Courses focused by the researcher to apply SOPHIE were BSc (Term 01-02 students: $n=20$ ) and Psychology (three groups in level 04, total number of students $=60$ ). Using purposive sampling a total of 80 students were included. Multiple or collective case study involves studying multiple cases simultaneously or sequentially to generate a broader appreciation of a particular issue studied in a given context (Yin 2009, 2014; Robson and McCartan 2016). A multiple case study design allowed the researcher to apply reflective tools and activities based on the SOPHIE framework. Multiple and embedded case studies enabled researcher to gather more compelling and robust evidences to establish the validity and reliability of the research finding and impact analysis. (Yin 2014; Robson and McCartan 2016). To inquire about the meaning-based teaching and subjective learning experiences, students were engaged in extensive reflective exercises using an interpretative and constructive research paradigm. (Robson and McCartan 2016; King and Brooks 2017). Epistemological reflections based on interpretive phenomenological methods served two purposes: 1 . It enabled social researchers to understand subjective constructs and ways of seeking knowledge to apprehend reality (Marczyk et al. 2005). 2. The methods helped to perform an open enquiry on how social realities were formed and perceived among students and how those can be integrated/transform as spiritual care competencies into undergraduate health and social care courses. The Program Manager and Research Directors of the University program were informed about integrating and using reflective practice activities in within the assigned courses and therefore no formal ethical clearance was required from the University Ethics Committee for the study. These innovative reflective activities became integral to learning and were part of the learning outcomes of each taught course.

\section{Practice Intervention}

The in-class interactive activities were designed by the researcher as the course lecturer in the university (Appendix A-Resources 01). No formal University Research Ethics clearance was required, as SOPHIE was introduced and implemented as an in-class teaching and learning practice methodology during Health and Social care modules in June 2019-2020 Students were facilitated to explore their existential quest and meaning making process by extensive self-reflection activities after learning about SOPHIE through in-class discussions and watching a videos on it; developed by the primary author as an online learning resource (Appendix A-Resources 01). In-class activities also included: practicing mindfulness, artwork, reflective writing, and reflexive group discussions to explore intra-spirituality and inter-spiritual care needs (Mooney and Timmins 2007; Schnell et al. 2013; EPICC 2019). However, confidentiality and data protection measures were carried out for students' safeguarding needs. 
Information sheet about SOPHIE framework along with a consent form was developed and provided to students prior to study participation. Verbal and written consent were obtained for data protection and confidentiality (Robson and McCartan 2016). Total four cohorts with $n=20$ students in each cohort participated. All students in each cohort, agreed to participate in the study to develop self-awareness about their own spiritual and existential care needs; allowing them to internalize and approach the spiritual care needs of others (Schnell et al. 2013). Students could choose how they want to participate in all in-class activities and discussions. Students were also allowed to share their experiences, values, and beliefs about spirituality and existential care needs; either as one-one or collectively in a group setting, draw or write their reflections on the worksheets provided by the researcher (Mooney and Timmins 2007). Separate anecdotes were made for shared verbal discussions in the class. Some participants were happy to disclose their spiritual and existential needs in groups. Others were provided one to one-private consultation as requested by the participants. Students were also allowed to choose their degree of participation during the class activities, if causing any distress (Schnell et al. 2013; Robson and McCartan 2016) and were also offered emotional support and counselling while sharing their experiences as requested. Participants were free to opt-out from the study; however, none declined. The data findings were kept anonymous and was only shared among the research team.

\section{Data Analysis}

Data was analyzed using narrative analysis to explore understandings of spirituality and meaning making in adult learning and education using SOPHIE framework. Narrative analysis is useful to explore the meaning making personal processes, and is embedded in the lives of the ordinary, the marginalized, and the muted, where personal narratives respond to the disintegration of master narratives as people make sense of experience, claim identities, and "get a life" by telling and writing their stories (Langellier 2001; Riessman and Quinney 2005). The stories shared by the people provide important information about their experience in relation to their identity and social life (Stephens and Breheny 2013). Using narrative analysis, researchers invested upon all collected stories, both verbal and written self-reflective activities, and did an inductive conceptual grouping from it. Data including narratives collected using anecdotal notes from verbal discussions and written activity sheets was read, analyzed, and reviewed critically to classify or create linkages in the data and to find underlying meanings and immediate impression of the data. All the narratives were organized under major themes, as a representational strategy based on group/individual reflections gathered among different cohorts/cases (Riessman and Quinney 2005). Various themes emerging across the data were re-analyzed, until no new themes could be identified. A constant comparative analysis was also done across different data sets to locate various similarities and variations among different characteristics embedded across the data gathered from all participants. Existing literature was also compared and reviewed simultaneously as the key patterns and linkages emerged in the data. Using an iterative approach, a final thematic list was generated from the data and was shared with other research team members for consensus and additional input. To ensure credibility and rigor, separate logbook, field notes, analytic and reflexive notes were also maintained throughout the study. A detailed audit trail was kept that followed a logical sequence where the reasoning behind each decision during different phases of the study (Riessman and Quinney 2005; Robson and McCartan 2016).

\section{The Findings}

Three major phases of self-exploration were identified during the in-class interventions, to understand and address spiritual care needs by applying SOPHIE. These phases are recognized as themes here, based on the data gathered through written reflection, illustrations, poetry, songs, and verbal narrative shared by students. The three major themes were access to self, engaging with self, and embracing self. 


\subsection{Access to Self}

Using the SOPHIE framework, participants were encouraged to verbalize, draw, or use any creative expression to reflect upon their identity construction by exploring: Who am I? Participants were asked to describe their self in ontological, existential, and ideological domains as outlined SOPHIE framework (Figure 2).

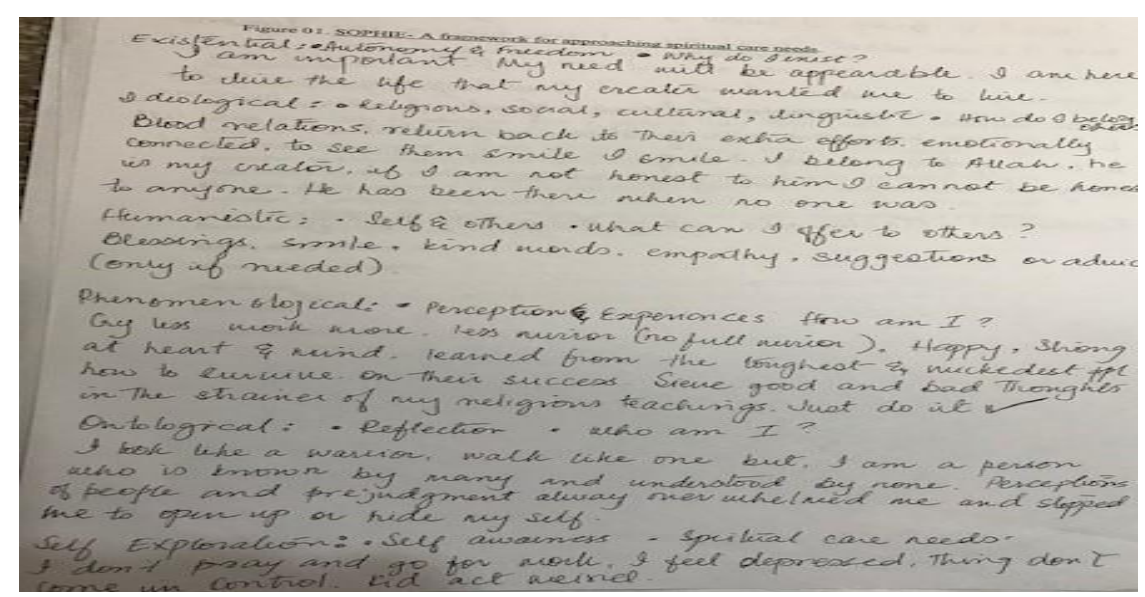

Figure 2. Student's Reflective account using SOPHIE.

For some participants, responses were rooted in their name, religion, social role and responsibility, nationality etc. Whereas some participants took an ontological and existential perspectives to describe their self. Such perspectives allowed participants to share and reflect on their inner self, painful experiences, anxieties, and vulnerabilities using art and other reflective activities. One of the participants accessed her individual self as,

"I don't want to be called by my name, as it reminds me of my past unhealthy relationship. My name is not my identity of who I am and what I see myself as. I have changed my name now. However, now I have realized that it was my existential pain, I was still carrying through!" (RAS-06/U2-G3)

A participant narrated her life struggle being a victim of domestic violence and mother of two young, less than five years old children. Reflecting on her self-identify, she drew a face-less woman, whose free and empowered youth has been lost in time. While sharing her struggles after marriage, she became tearful and said,

“I want my heels back!" (MSM-01/U1-G2) (Figure 3)

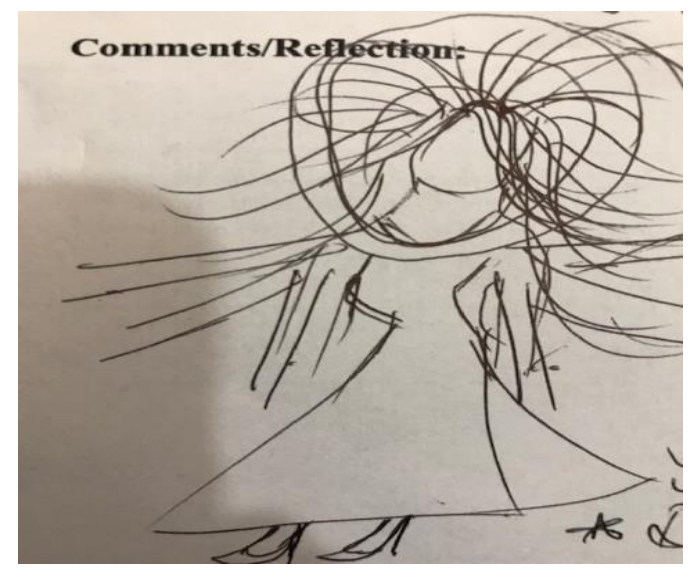

Figure 3. Faceless woman wanting heels back! 
Another participant who recently had consecutive miscarriages drew a face with bleeding tears (Figure 4). She was trying to have a baby for some time. Within the existential domain of SOPHIE, she described herself as,

“I have lost my baby once again over the last one year. I don't know if I can be a mum again! I don't know what it is to be me?" (AGB-U1-G1)

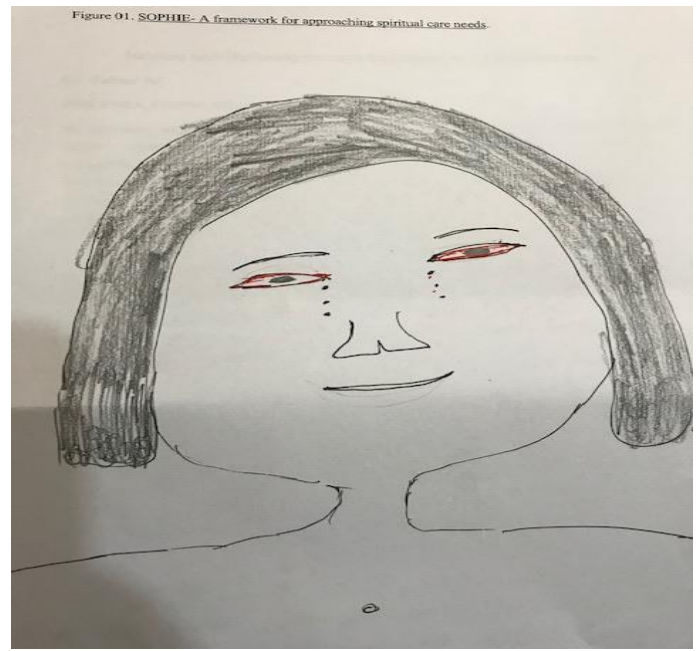

Figure 4. Bleeding tears.

A young mum identified her masked self. She questioned her ideological self to reflect upon her existence and what gives her meaning in life. She questioned her faith, society, and expectations versus her own ideological values and beliefs and explored her personal being a free-self versus good and pious as,

“I don't know what it is and who am I? I am dyslexic with two twins suffering from learning disability. I am a practicing Muslim, but I don't know why I have got so many difficult and unhappy relationships in my life. Why me? I have to pretend to be as expected by others around me. I am tired of wearing a mask". (NMM-U2-G4)

One of the participants shared her existential and spiritual need by drew a turtle. She identified herself as vulnerable, shy, and quite person. She shared that,

"I lost my parents when I was young. Nobody can see my real self and I want to hide myself from everyone. I think I don't trust anyone and that is my existential and spiritual need". (TUS-U2-G3) (Figure 5)

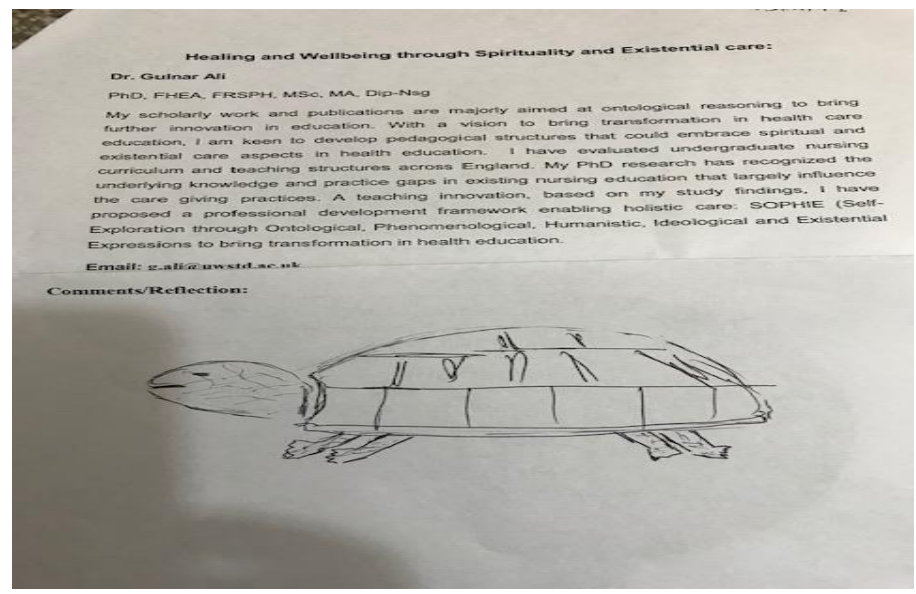

Figure 5. Hiding self as Turtle. 
Another participant having a pre-mature baby birth shared her motherhood experience and expressed her happy self as,

“Nobody believed that my baby will survive, I haven't seen such tiny baby. But he is thriving now. I don't know whether he will be able to speak and call me mum ever ..., (tearful). He is three-year old now, but he just makes few sounds and looks at me as he knows I am his mother. He is very slow in responding. But I can feel the connection and that means all to me!" (ANG-U1-G1)

Findings indicated that participants shared their vulnerabilities and adversities while discussing their self-care needs. Different metaphors and expressions were used to describe personal existential needs. They were also able to internalize their sufferings and how those sufferings shaped their actual/real self. For some, sufferings also brought opportunities, provided them courage, and made then resilient. Using SOPHIE as a reflexive tool, encouraged students to access and explore their deeper existential care needs.

\subsection{Engaging with Self}

As students identified their hidden beliefs, known and unknown trauma, fear, loss, and meaninglessness about life, relationship crisis and autonomy issues, the researcher facilitated participants to further identify some constructive approaches to address their spiritual and existential needs. To offer self-compassion and engagement, students were encouraged to practice mindfulness by the researcher. Mindfulness as a reflective practice activity was also part of in-class activities embedded in the courses. The researcher used flowers, leaves and stones to engage students to experience, being in the moment (WYS-U2, G6). Students were encouraged to identify their thought patterns, choice of emotions and behavior patterns in life. Participants were encouraged to practice mindfulness, while touching those objects and accepting themselves, as they are. The time duration was 20-min for practicing mindfulness and reflexivity. Students were encouraged to reflect on their own thoughts and feelings, based on their personal and professional experiences, while practicing mindfulness. For some participants, the activity was found to be helpful as they could feel relaxed and at peace within. Whereas for some, it was difficult to practice mindfulness, as they could not stop thinking about their past (TMS-U1- G4, OIU-U2, G5) or loss in life due to health issues or relationship failures. Some students found difficulty concentrating, and few reported uncomfortable, while dealing with thoughts that reminded them of past events or memories with heavy feelings of self-blame, anxiety, fear, shame, and self-doubt. At this stage, students were offered one-to-one support by the lecturer, where requested by the participants. As a group, when learners shared personal stories of loss or bereavement, they were also encouraged to offer self-compassion and practice offering compassionated presence and openness towards each other.

\subsection{Embracing Self}

Using poetry, art and other reflective activities, participants also reported greater sense of empowerment, liberation, and clarity about their spiritual and existential care needs. The loss and doubts experiences among participants were presented in-class through poetry writing. The journey of empowerment through self-care interventions was shared as,

"I give time and care

I build hope and understanding

You judge and tear down break hope in time of need

You follow policy and show no care

I lose hope and leave

I will grow and I will learn and move on 
I will give care again". (BNJ-U1, G1)

Another student expressed her suffering and meaning making process as,

\section{“WHO KNOWS?}

Legs shaky, breath week, voice interrupted, tears flowed

Wheelchair rushed for my support

X-ray shows perfect lungs, so why do I feel deaths thumbs

Doctors reassure, 'COVID-19 is not at your door'

So why do I feel death's claw?

Familiar voices call to say hi, but with gasping breath I say goodbye" (GBY, U1, G2)

Findings indicated that using SOPHIE framework as a practice methodology allowed students to acknowledge personal values and beliefs about experiences of fear, guilt, and inhibitions. It also provided students a sense of engagement with self by identifying the nature of conflict between choices and meaning making process. It also helped them to reflect on their existential self, find meaning and hope, and connect with self and others (Figure 6).

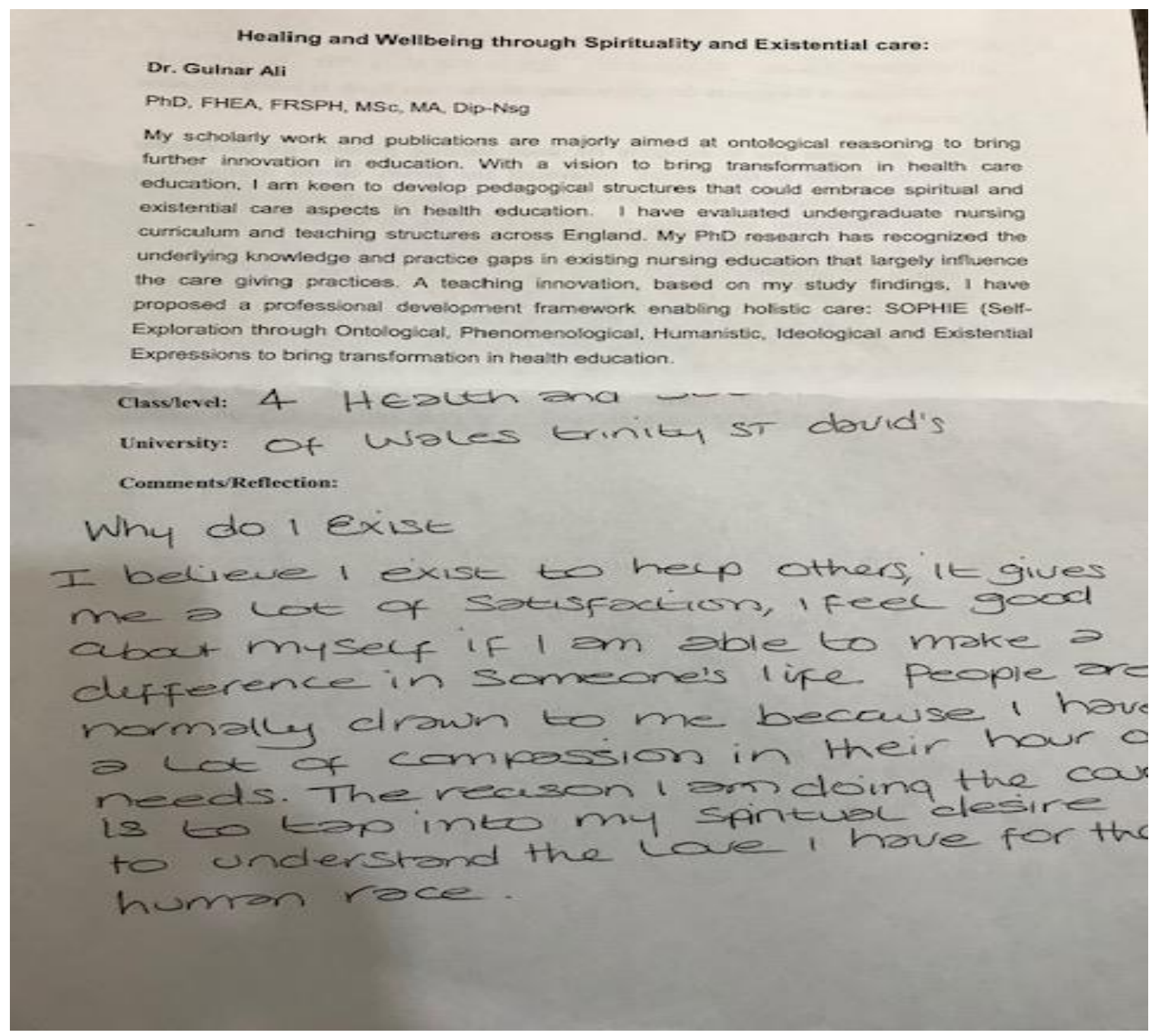

Figure 6. Engaging with belief patterns. 
Self-exploration using SOPHIE, also enabled participants to identify the role of perception and intentionality in making-making process, affecting authenticity, and empowerment across life-choices (Figure 7).

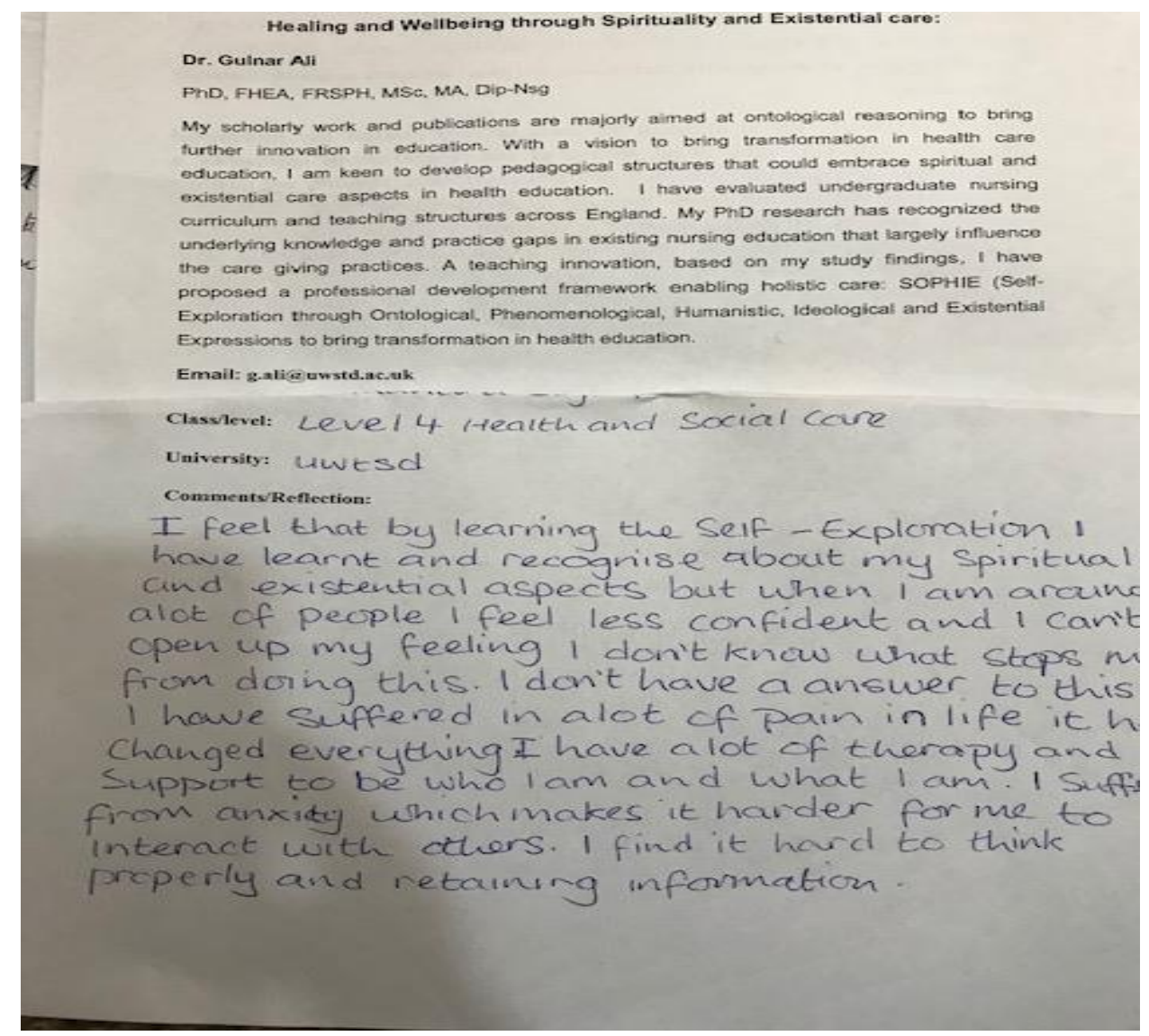

Figure 7. Finding self.

Some students required 1:1 consultations and scheduled appointment for mentorship and further counselling. Emotional support was offered after each session for individual students as per their needs. Students found relaxed and reported empowered after each consultation. Students' formative and summative assessments also reported good results and outstanding progress in taught learning modules. Students developed clarity about their career aspiration to be a care giver, by acknowledging their own existential and spiritual care needs. One student reported that,

"I can see now what was my problem. I think I also had the power to choose and decide to be happy, whatever life has offered to me. I want to sing and release all my tears and pain .... (She sang self-written poetry with tears in her eyes.)" (MMG. 100, U1/G5)

Another student said,

"I was sad as I did not get any flowers while we were practicing mindfulness. (Everybody laughed). But even with a stone, I feel happy now. Sometimes, we can't choose what life offers to us. It is not under our control. The choice is ours to be happy or resentful about it. I think I can see how my thinking and emotions are controlling me. I choose to be free and be at peace with myself, by controlling my thoughts about all past relationship failures". (SSM, 87-U2/G6)

Students were encouraged to design their own ideas based on their personal and professional experiences by embracing their own authentic self and recognizing their own set of values towards 
self-care and professional growth. Such learning process, finding their own inner spaces using heutagogical engagement, allowed each student to actively participate in his/her knowledge creation and professional transformation.

\section{Discussion}

Findings strongly supported that using SOPHIE as a reflexive tool facilitated students to focus upon existential ideas and develop more understanding about self and self-care needs. SOPHIE allowed participants to recognize the power of authenticity, self-awareness, intentionality, creativity, and empowerment as core domains of spirituality, impacting existential health of a person. Deep learning approaches engages learners to be more reflexive about their choices and empower them as a self-directed learner (Higgs 2019). Sinclair et al. (2016) study also indicate that healthcare students and practicing clinicians report that reflecting on personal beliefs, personal experiences with illness, and experiences of receiving compassion, act as catalysts for developing compassion and compassionate values. In class reflective activities also generated a spirit of tolerance and social inclusion among learners; appreciating pluralistic views and self-directed learning (Snowden et al. 2016). Utilizing the principles of deep learning, students were found empowered, critical and creative in recognizing their own vulnerabilities as well as their strength. Self-exploration requires embracing an authentic and congruent self (Wattis et al. 2019). By acknowledging personal strengths and recognizing needs for self-development, students reflected upon the underlying meaning-making process, a vital part of spirituality, as well as behavioral patterns and personal choices. By taking charge of one's own thinking, feelings, and actions; an empowered, motivated, and determined self was developed among the students. (Ali 2017).

The SOPHIE framework allowed students to generate their individual self-care needs in various dimensions such as ontological, phenomenological, humanistic, ideological, and existential domains. From an ontological perspective, the personal sense of "being and becoming", allowed students to engage with the philosophical reasoning associated with the meaning of their existence in the given time. SOPHIE enhanced the students' ability to identify personal resources of hope and connection in their own as well as other people's lives (Kierkegaard 2000; Martinsen 2006; Rogers 2016). The phenomenological domain explored their perceptions, feelings, and experiences using activities such as applied mindfulness and artistic expression through drawing a personal sense of self and poetry writing. The activities promoted self-efficacy and healing through intentionality (Zahourek 2005), defined as, "focused attention" or "mental projection of awareness, with purpose and efficacy, towards some object or outcome, such as promoting change in one's self or another" (Braud and Marilyn 1991, p. 31). Hence, by exploring one's thought constructs, affective responses, and behavioral reactions, students developed insight about feelings and responses developed in the given situation, influencing their coping and self-efficacy (Ali 2017). The humanistic domain focused on generating compassionate values for others, referred to as how one's self is presented in society for others (Carlin et al. 2012). The findings supported that group discussions allowed participants to explore the extent of self-availability. Self-extension was achieved by acting compassionately, offering caring presence, effective listening, and by providing existential advocacy for others (Rogers 2016). By exploring the humanistic dimension, participants recognized their strengths and areas of challenge in relating to others. Such realization helped participants to overcome emotional and behavioral resistance, hindering the realization of personal potentials (Newman 1999; Flaming 2004; Wattis et al. 2019). Whilst the ideological domain explored religious, cultural, social, political, and linguistic aspects that affects self-identity within a given context. Knowledge of such affiliations enabled students to acknowledge various values, beliefs, doctrines, and traditions and to maintain the privacy and dignity (Ali 2017). The in-class reflective activities also generated a spirit of tolerance and social inclusion among learners; appreciating pluralistic views and self-directed learning (Snowden et al. 2016). The existential domain focused on one's quest in life and allowed participants to explore what influences their self-identity constructs and how it often affects their wellbeing (Kang 2003; Higgs 2019). Such exploration was 
found very useful in recognizing the meaning of suffering and hope in participants' life, in exploring identity crisis, gender issues, sexual anxieties, social fears, and nature of loss and pain, affecting personal growth and recovery (Moore and Goldner-Vukov 2009).

\section{Future Implications and Conclusions}

Self-reflective practices in health education are integral in recognizing existential and spiritual care needs of self and others by reflecting on self-behavioral responses and belief patterns. It is essential to recognize and reflect on how our own personhood impacts our clinical relationships and care aspects with the patients and families in the practice settings (Chochinov et al. 2013). Healthcare educators should integrate spiritual dimensions and use meaningful spiritual competency tools in both education and practice settings to enhance the provision of quality healthcare. SOPHIE can be used as a meaningful pedagogical tool to recognize selfcare needs, generate discussions around own existence, and articulation of self among students in higher education. SOPHIE framework guided us in developing and implementing activities such as self-reflection, mentorship, counselling, and peer support. These activities enabled students to reflect on their self-identity, spiritual and existential needs, meaningful connections, and compassionate values, fundamental to the delivery of holistic person-centered care. The findings of our study indicated that students developed authenticity towards their personal and professional responsibilities as prospective healthcare providers. Moreover, students were found inspired and self-motivated towards their professional aspirations and commitments to care, acknowledging their own existential and spiritual care needs. The activities allowed students to learn the importance of offering self-compassion, therapeutic listening, and caring presence integral for the provision of spiritually competent person-centered care in practice settings. Further research is recommended to assess the utility and generalizability of SOPHIE as a reflexive tool in both teaching and care practice.

Author Contributions: Conceptualization, G.A.; methodology, G.A.; software, G.A. and N.L.; validation, G.A. and N.L.; formal analysis, G.A.; investigation, G.A.; resources, G.A.; data curation, G.A.; writing-original draft preparation, G.A.; writing - review and editing, G.A. and N.L.; visualization, G.A. and N.L.; supervision, G.A.; project administration, G.A. All authors have read and agreed to the published version of the manuscript.

Funding: This research received no external funding.

Acknowledgments: Inspiration from EPICC Network Enhancing Nurses' and Midwives' Competence in Providing Spiritual Care through Innovative Education and Compassionate Care-EPICC Adoption Toolkit. http://blogs.staffs. ac.uk/epicc/resources/epicc-adoption-toolkit/.

Conflicts of Interest: There is no conflict of interest to disclose.

\section{Appendix A}

YouTube video developed by Gulnar Ali on SOPHIE, as an online resource to discuss spiritual care needs. Resource 01: SOPHIE-A framework to approach and address Spiritual care needs-Gulnar Ali. www.gulnarali.org, YouTube video on SOPHIE—https://www.youtube.com/watch?v=16e7W51uYwE.

\section{References}

Ali, Gulnar, and Michael Snowden. 2019. SOPHIE (Self-Exploration through Ontological, Phenomenological, Humanistic, Ideological and Existential Expressions): A Mentoring Framework. In Mentorship, Leadership, and Research. International Perspectives on Social Policy, Administration, and Practice. Edited by M. Snowden and J. Halsall. Cham: Springer.

Ali, Gulnar, Michael Snowden, John Wattis, and Melanie Rogers. 2018. Spirituality in nursing education: Knowledge and practice gaps. International Journal of Multidisciplinary Comparative Studies 5: 27-49.

Ali, Gulnar. 2017. Multiple Case Studies Exploring Integration of Spirituality in Undergraduate Nursing Education in England. Ph.D. Thesis, University of Huddersfield, Huddersfield, UK. Available online: http://eprints.hud.ac.uk/id/eprint/34129 (accessed on 3 September 2020). 
Braud, William, and Schlitz Marilyn. 1991. Conscious interactions with remote biological systems: Anomalous intentionality effects. Subtle Energies 2: 1-45.

Caldeira, Sílvia; Amélia Simões Figueiredo, Ana Paula da Conceição, Célia Ermel, João Mendes, Erika Chaves, Emília Campos de Carvalho, and Margarida Vieira. 2016. Spirituality in the Undergraduate Curricula of Nursing Schools in Portugal and São Paulo-Brazil. Religions 7: 134. [CrossRef]

Carlin, Nathan, Cole Thomas, and Henry Strobel. 2012. Guidance from the humanities for professional formation. In Oxford Textbook of Spirituality in Healthcare. Edited by M. Cobb, C. Puchalski and B. Rumbold. Oxford: Oxford University Press.

Chochinov, Harvey M., Susan E. McClement, Thomas F. Hack, Nancy A. McKeen, Amanda M. Rach, Pierre Gagnon, Shane Sinclair, and Jill Taylor-Brown. 2013. Healthcare provider communication: An empirical model of therapeutic effectiveness. Cancer 119: 1703-13. [CrossRef] [PubMed]

EPICC. 2019. EPICC Network Enhancing Nurses' and Midwives' Competence in Providing Spiritual Care through Innovative Education and Compassionate Care-Adoption Toolkit. Available online: http://blogs.staffs.ac.uk/ epicc/resources/epicc-adoption-toolkit/ (accessed on 20 July 2020).

Flaming, Don. 2004. Nursing theories as nursing ontologies. Nursing Philosophy 5: 224-29. [CrossRef] [PubMed] Higgs, Joy. 2019. Practice Wisdom: Values and Interpretations. Leiden: BRILL.

Kalkim, Asli, Tulay Midilli, and Baysal Ebru. 2016. An Investigation of the Perceptions and Practices of Nursing Students Regarding Spirituality and Spiritual Care. Religions 7: 101. [CrossRef]

Kierkegaard, Soren. 2000. The Essential Kierkegaard. Princeton: Princeton University Press.

King, Nigel, and Joanna Brooks. 2017. Template Analysis. London: Sage.

Kang, Chris. 2003. A psycho spiritual integration frame of reference for occupational therapy. Part 1: Conceptual foundations. Australian Journal of Occupational Therapy 50: 92-103. [CrossRef]

Koenig, Harold. 2004. Religion, Spirituality and Medicine: Research—Findings and Implications for Clinical Practice. Southern Medical Journal 97: 1194-200. [CrossRef] [PubMed]

Lalani, Nasreen. 2020. Meanings and Interpretations of Spirituality in Nursing and Health. Religions 11: 428. [CrossRef]

Langellier, Kristin. 2001. Personal narrative. In Encyclopaedia of Life Writing: Autobiographical and Biographical Forms. Edited by M. Jolly and Fitzroy Dearborn. London: Fitzroy, vol. 2.

Marczyk, Geoffery, David DeMatteo, and David Festinger. 2005. Essentials of Research Design and Methodology. Hoboken: John Wiley and Sons, Inc.

Martinsen, Kari. 2006. Care and Vulnerability. Oslo: Akribe.

Mooney, Brona, and Fiona Timmins. 2007. Spirituality as a universal Concept: Student experience of learning about Spirituality through the medium of Art. Nurse Education in Practice 7: 275-84. [CrossRef] [PubMed]

Moore, Laurie J., and Mila Goldner-Vukov. 2009. The existential way to recovery. Psychiatria Danubina 21: 453-62. [PubMed]

Newman, Margaret A. 1999. Health as Expanding Consciousness. New York: National League for Nursing Press.

Robson, Colin, and Kieran McCartan. 2016. Real World Research, 4th ed. Hoboken: Wiley.

Rogers, Melanie. 2016. Utilising Availability and Vulnerability to operationalise spirituality'. In Practising Spirituality. London: Palgrave Macmillan, pp. 145-64. ISBN 9781137556844.

Riessman, Kohler, and Lee Quinney. 2005. Narrative in social work: A critical review. Qualitative Social Work 4: 391-412. [CrossRef]

Schnell, Tatjana, Thomas Höge, and Edith Pollet. 2013. Predicting meaning in work: Theory, data, implications. The Journal of Positive Psychology 8: 543-54. [CrossRef]

Sinclair, Shane Mia-Bernadine Torres, Shelley Raffin-Bouchal, Thomas F. Hack, Susan McClement, Neil A. Hagen, and Harvey M. Chochinov. 2016. Compassion training in healthcare: What are patients' perspectives on training healthcare providers? BMC Medical Education 16: 169. [CrossRef] [PubMed]

Snowden, Michael, Jamie Halsall, and Yvonne Huang. 2016. Self-determined approach to learning: A social science perspective. Cogent Education 3: 1247608. [CrossRef]

Stephens, Chirstine, and Mary Breheny. 2013. Narrative analysis in psychological research: An integrated approach to interpreting stories. Qualitative Research in Psychology 10: 14-27. [CrossRef]

Tisdell, Elizabeth. 2001. Spirituality in Adult and Higher Education. ERIC Digest. Available online: https: //files.eric.ed.gov/fulltext/ED459370.pdf (accessed on 30 July 2020). 
Tisdell, Elizabeth, and Derise Tolliver. 2003. Claiming a Sacred Face: The Role of Spirituality and Cultural Identity in Transformative Adult Higher Education. Journal of Transformative Education 1: 368-92. [CrossRef]

Wattis, John, Stephen Curran, and Melanie Rogers. 2017. Spiritually Competent Practice in Health Care. London: CRC Press Taylor and Francis Group, ISBN 9781138739116.

Wattis, John, Melanie Rogers, Gulnar Ali, and Stephen Curran. 2019. Bringing Spirituality and Wisdom into Practice. In Practice Wisdom. Leiden: BRILL, pp. 155-68. [CrossRef]

Yin, Robert. 2009. Case Study Research Design and Methods, 4th ed. Washington: Sage.

Yin, Robert. 2014. Case Study Research: Design and Methods, 5th ed. Thousand Oaks: SAGE.

Zahourek, Rothyln. 2005. Intentionality: Evolutionary Development in Healing. A Grounded Theory Study for Holistic Nursing. Journal of holistic Nursing 23: 89-109. [CrossRef] [PubMed]

(C) 2020 by the authors. Licensee MDPI, Basel, Switzerland. This article is an open access article distributed under the terms and conditions of the Creative Commons Attribution (CC BY) license (http://creativecommons.org/licenses/by/4.0/). 